Pacific Journal of Mathematic 


\title{
CONDITIONS IMPLYING NORMALITY IN HILBERT SPACE
}

\author{
MARY R. EMBRY
}

The problem with which this paper is concerned is that of finding new conditions which imply the normality of an operator on a complete inner product space $S$. Each such condition, presented in this paper, involves the commutativity of certain operators, associated with a given operator $A$. Theorem 1 states the equivalence of the following conditions: (i) $A$ is normal, (ii) each of $A A^{*}$ and $A^{*} A$ commutes with $\operatorname{Re} A$, (iii) $A A^{*}$ commutes with $\operatorname{Re} A$ and $A^{*} A$ commutes with $\operatorname{Im} A$. Theorem 2 states that $A$ is normal if $A A^{*}$ and $A^{*} A$ commute and $\operatorname{Re} A$ is nonnegative definite. Finally, Theorem 3 states that if $A A^{*}$ commutes with each of $A^{*} A$ and $\operatorname{Re} A$, then $A A^{*}$ commutes with $A$. In this case, if $A$ is reversible, then $A$ is normal.

The notation and terminology used will be as follows. $S$ is a complex, linear space and $Q$ is an inner product for $S$, such that $S$ is complete with respect to the norm $N$, induced by $Q . T$ is the space of linear operators on $S$ to $S$, continuous with respect to $N$. If $A$ is in $T, A^{*}$ is the adjoint of $A$ with respect to $Q, \operatorname{Re} A=$ $\left(A+A^{*}\right) / 2$, and $\operatorname{Im} A=\left(A-A^{*}\right) / 2 i$. An element $A$ of $T$ is nonnegative definite if $Q(A x, x) \geqq 0$ for each $x$ in $S$, Hermitian if $A=$ $A^{*}$, normal if $A A^{*}=A^{*} A$, reversible if $A$ is one-to-one, and invertible if $A$ is one-to-one and onto.

The following special notation will be used throughout the paper. Let $B^{2}=A A^{*}$ and $C^{2}=A^{*} A$, where $B$ and $C$ are nonnegative definite. $b$ and $c$ will denote the spectral resolutions of $B^{2}$ and $C^{2}$, respectively (1, pp. 114-116). These spectral resolutions will be taken to be continuous from the right at each point.

One can see from the following example that relatively strong hypotheses on operators associated with $A$ are necessary in order that $A$ be normal. Let $A$ be the operator on $l_{2}$, defined by $A=\left\{a_{i, j}\right\}_{i, j=1}^{\infty}$ where $a_{i, i+1}=1$ and $a_{i, j}=0$ for $j \neq i+1$. Then $B=1$ and $C=P$, where $P$ is a certain projection not equal to 1 or 0 . Since $B=1$, then $B$ commutes with $C, \operatorname{Re} A, \operatorname{Im} A$, and even with $A$ itself. However, $A$ is not normal.

2. Commutativity relations concerning $\mathbf{B}$ and $\mathbf{C}$.

THEOREM 1. The following are equivalent:

(i) $A$ is normal, 
(ii) each of $B$ and $C$ commutes with $\operatorname{Re} A$,

(iii) $B$ commutes with $\operatorname{Re} A$ and $C$ commutes with $\operatorname{Im} A$.

Proof. That (i) implies (ii) and (iii) is obvious. Let $H=\operatorname{Re} A$ and $K=\operatorname{Im} A$.

(ii) $\Rightarrow$ (i). If $H B^{2}=B^{2} H$ and $H C^{2}=C^{2} H$, then one has

$$
\begin{aligned}
A\left(B^{2}-C^{2}\right) & =\left(B^{2}-C^{2}\right) A^{*} \\
\text { and } \quad A^{*}\left(B^{2}-C^{2}\right) & =\left(B^{2}-C^{2}\right) A .
\end{aligned}
$$

Multiplying (1) on the left by $A^{*}$ and using (2), one finds that

$$
C^{2}\left(B^{2}-C^{2}\right)=\left(B^{2}-C^{2}\right) B^{2} \text {. }
$$

Multiplying (2) on the left by $A$ and using (1), one has

$$
B^{2}\left(B^{2}-C^{2}\right)=\left(B^{2}-C^{2}\right) C^{2} .
$$

Subtracting (4) from (3), one sees that $\left(B^{2}-C^{2}\right)^{2}=-\left(B^{2}-C^{2}\right)^{2}$. Therefore, $B^{2}=C^{2}$, and $A$ is normal.

(iii) $\Rightarrow$ (i). If $K C^{2}=C^{2} K$, then

$$
\left(B^{2}-C^{2}\right) A=-A^{*}\left(B^{2}-C^{2}\right) .
$$

Multiplying (5) on the left by $A$ and using (1), one has $-B^{2}\left(B^{2}-C^{2}\right)=$ $\left(B^{2}-C^{2}\right) C^{2}$. Therefore, $B^{4}=C^{4}$, and $B^{2}=C^{2}$ (2, p. 262).

Lemma 2.1. (i) $A\left[\int f(t) d c\right]=\left[\int f(t) d b\right] A$, for each continuous complex-valued function on the real line.

(ii) $A C^{n}=B^{n} A$, for each positive integer $n$.

(iii) $A c(t)=b(t) A$, for each value of $t$.

Proof. (i) By definition of $B^{2}$ and $C^{2}, A C^{2 n}=B^{2 n} A$ for each positive integer $n$. Therefore, $A\left[\int t^{n} d c\right]=\left[\int t^{n} d b\right] A$ for each nonnegative integer $n$. The desired result follows by use of the Weierstrass approximation theorem. (ii) and (iii) are both special cases of (i).

TheOREM 2. If $B C=C B$ and $\operatorname{Re} A$ is nonnegative definite, then $A$ is normal.

Proof. Let $t$ be a real number and let $H=\operatorname{Re} A$ and $K=\operatorname{Im} A$. Define $k(t)=[1-c(t)] A c(t)$ and $n(t)=c(t) A[1-c(t)]$. Then, using Lemma 2.1, one finds that $A k(t)^{*}(S) \subset k(t)(s)$ and $A n(t)^{*}(S) \subset n(t)(S)$. Since $k(t)^{2}=0 \quad$ and $n(t)^{2}=0, \quad k(t) A k(t)^{*}=0 \quad$ and $n(t) A n(t)^{*}=0$. 
Therefore, $k(t) H k(t)^{*}=0$ and $n(t) H n(t)^{*}=0$. Since $H$ is nonnegative definite, then $H k(t)^{*}=H n(t)^{*}=0$. Substituting for $k(t)$ and $n(t)$, one sees that

$$
\begin{aligned}
& H[1-c(t)] A^{*} c(t)=0 \quad \text { and } \\
& H c(t) A^{*}[1-c(t)]=0 .
\end{aligned}
$$

Subtracting (2) from (1) gives

$$
\begin{aligned}
& H\left[A^{*} c(t)-c(t) A^{*}\right]=0, \text { so that } \\
& H A^{*}[c(t)-b(t)]=0 \text { by Lemma } 2.1 .
\end{aligned}
$$

In an analogous fashion, using $p(t)=[1-b(t)] A^{*} b(t)$ and $q(t)=$ $b(t) A^{*}[1-b(t)]$, one arrives at

$$
H A[b(t)-c(t)]=0 .
$$

Combining (3) and (4), one finds that $H K[b(t)-c(t)]=0$ and $H^{2}[b(t)-c(t)]=0$. Then $H[b(t)-c(t)]=0$. A simple calculation shows that $B^{2}-C^{2}=2 i(K H-H K)$. Combining these last three equations, one has $\left(B^{2}-C^{2}\right)(b(t)-c(t))=0$. Since $t$ was arbitrary, then $\left(B^{2}-C^{2}\right)^{2}=B^{2}-C^{2}=0$ and $A$ is normal.

THEOREM 3. If $B$ commutes with each of $C$ and Re $A$, then $B$ commutes with $A$. Moreover, in this case, if $A$ is reversible, then $A$ is normal.

Indication of proof. The final conclusion follows easily from Lemma 2.1. Again let $H=\operatorname{Re} A$ and $K=\operatorname{Im} A$. By use of the hypotheses, Lemma 2.1, and certain algebraic manipulations, one can show the following:

$$
\begin{aligned}
& (B-C) C H=0 \\
& (B-C) H(B-C)=0 \\
& C(C H-H C) C=0 \\
& A H A^{*} B=B A H A^{*} \text { and } \\
& A\left(B^{2}-C^{2}\right) B^{2}=A C^{2}\left(B^{2}-C^{2}\right)=0 .
\end{aligned}
$$

This final equation then implies that $A\left(B^{2}-C^{2}\right)=0$. Therefore, by Lemma 2.1, $A B^{2}=B^{2} A$. Since $B^{2}$ commutes with $A$, so does $B$ (2, p. 260).

In concluding this paper, I should like to note that the proofs of Theorems 2 and 3 can be made much simpler algebraically, if it is assumed that $A$ is invertible. However, it seemed reasonable to make the extra effort to prove the theorems without this added hypothesis. 
I should also like to note that Lemma 2.1 appeared in my doctoral thesis at the University of North Carolina. Theorems 2 and 3 appeared in the same thesis with the added hypothesis of invertibility of $A$. Again I would like to thank Dr. J. S. Mac Nerney of the Department of Mathematics of the University of North Carolina for the direction of my doctoral thesis.

\section{BIBLIOGRAPHY}

1. J. von Neumann, Allgemeine Eigenwerttheorie Hermitscher Funktionaloperatoren, Mathematische Annalen 102 (1929), 49-131.

2. F. Riesz and B. Sz. -Nagy, Leçons d'analyse fonctionelle, Akademiai Kiado, Budapest, 1952.

Received June 4, 1965.

The University of North Carolina at Charlotte 


\section{PACIFIC JOURNAL OF MATHEMATICS}

\section{EDITORS}

\author{
H. SAMELSON, \\ Stanford University \\ Stanford, California \\ R. M. BLUMENTHAL \\ University of Washington \\ Seattle, Washington 98105
}

\author{
*J. DugundJI \\ University of Southern California \\ Los Angeles, California 90007 \\ RICHARD ARENS \\ University of California \\ Los Angeles, California 90024
}

\section{ASSOCIATE EDITORS}
E. F. BECKENBACH
B. H. NeUmanN
F. WOLF
K. YOSIDA

\section{SUPPORTING INSTITUTIONS}

\author{
UNIVERSITY OF BRITISH COLUMBIA \\ CALIFORNIA INSTITUTE OF TECHNOLOGY \\ UNIVERSITY OF CALIFORNIA \\ MONTANA STATE UNIVERSITY \\ UNIVERSITY OF NEVADA \\ NEW MEXICO STATE UNIVERSITY \\ OREGON STATE UNIVERSITY \\ UNIVERSITY OF OREGON \\ OSAKA UNIVERSITY \\ UNIVERSITY OF SOUTHERN CALIFORNIA
}

\author{
STANFORD UNIVERSITY \\ UNIVERSITY OF TOKYO \\ UNIVERSITY OF UTAH \\ WASHINGTON STATE UNIVERSITY \\ UNIVERSITY OF WASHINGTON \\ * * * \\ AMERICAN MATHEMATICAL SOCIETY \\ CHEVRON RESEARCH CORPORATION \\ TRW SYSTEMS \\ NAVAL ORDNANCE TEST STATION
}

Mathematical papers intended for publication in the Pacific Journal of Mathematics should be typewritten (double spaced). The first paragraph or two must be capable of being used separately as a synopsis of the entire paper. It should not contain references to the bibliography. Manuscripts may be sent to any one of the four editors. All other communications to the editors should be addressed to the managing editor, Richard Arens at the University of California, Los Angeles, California 90024 .

50 reprints per author of each article are furnished free of charge; additional copies may be obtained at cost in multiples of 50 .

The Pacific Journal of Mathematics is published monthly. Effective with Volume 16 the price per volume (3 numbers) is $\$ 8.00$; single issues, $\$ 3.00$. Special price for current issues to individual faculty members of supporting institutions and to individual members of the American Mathematical Society: $\$ 4.00$ per volume; single issues $\$ 1.50$. Back numbers are available.

Subscriptions, orders for back numbers, and changes of address should be sent to Pacific Journal of Mathematics, 103 Highland Boulevard, Berkeley 8, California.

Printed at Kokusai Bunken Insatsusha (International Academic Printing Co., Ltd.), No. 6, 2-chome, Fujimi-cho, Chiyoda-ku, Tokyo, Japan.

PUBLISHED BY PACIFIC JOURNAL OF MATHEMATICS, A NON-PROFIT CORPORATION

The Supporting Institutions listed above contribute to the cost of publication of this Journal, but they are not owners or publishers and have no responsibility for its content or policies.

* Paul A. White, Acting Editor until J. Dugundji returns. 


\section{Pacific Journal of Mathematics}

\section{Vol. 18, No. 3 \\ May, 1966}

William George Bade and Philip C. Curtis, Jr., Embedding theorems for commutative Banach algebras .......................... 391

Wilfred Eaton Barnes, On the $\Gamma$-rings of Nobusawa ................. 411

J. D. Brooks, Second order dissipative operators ................ 423

Selwyn Ross Caradus, Operators with finite ascent and descent ........ 437

Earl A. Coddington and Anton Zettl, Hermitian and anti-hermitian properties of Green's matrices .......................... 451

Robert Arnold Di Paola, On sets represented by the same formula in distinct consistent axiomatizable Rosser theories ................... 455

Mary Rodriguez Embry, Conditions implying normality in Hilbert space ...........................................

Garth Ian Gaudry, Quasimeasures and operators commuting with convolution ................................... 461

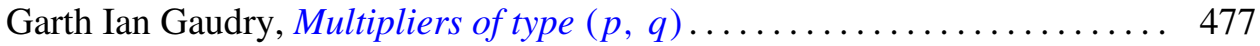

Ernest Lyle Griffin, Jr., Everywhere defined linear transformations affiliated with rings of operators .................................. 489

Philip Hartman, On the bounded slope condition ................ 495

David Wilson Henderson, Relative general position ................ 513

William Branham Jones, Duality and types of completeness in locally

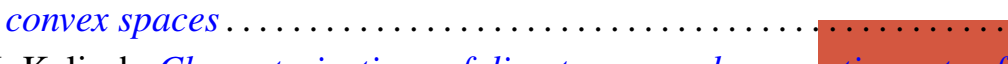

G. K. Kalisch, Characterizations of direct sums and commuting sets of Volterra operators....

Ottmar Loos, Über eine Beziehung zwischen Malcev-Algebren und Lietripelsystemen

Ronson Joseph Warne, A class of bisimple inverse semigroups . . . 